\section{B) Observatori de \\ Bioètica i Dret}

ISSN: $1886-5887$

\section{Revista de Bioética y Derecho}

Publicación del Máster en Bioética y Derecho nww.bioeticayderecho.ub.edu

DESDE EL MÁSTER

\title{
Las cosas por su nombre: ¿Objeción de conciencia o desobediencia civil? ${ }^{1}$
}

\author{
Things by their name: Consciousness objection or civil \\ disobedience? ${ }^{1}$
}

Sílvia NAVARRo CASADO*

En esta sección tienen cabida las aportaciones de los alumnos del Máster en Bioética y Derecho de la Universitat de Barcelona, de la presente edición (XV Promoción 2012-2013) así como de ediciones anteriores. Esperamos vuestras contribuciones en obd2@ub.edu.

\footnotetext{
1 Tras la aceptación de este artículo, en Cataluña el conseller de salud de la Generalitat, Boi Ruiz, ha manifestado públicamente que se proporcionará tarjeta sanitaria a los inmigrantes irregulares censados en la región porque "no se puede dejar a nadie sin asistencia sanitaria porque no tengan residencia administrativa". Para el conseller, esta medida amplía el Real Decreto del Gobierno central sobre sanidad, ya que permite a los inmigrantes 'sin papeles' el acceso a la atención primaria y no solo a las urgencias y a la atención materno infantil. Se prevé que el número de tarjetas expedido sea de más de 100.000 .

Declaraciones realizadas en Marzo de 2013. Para más información consúltese el siguiente enlace http://www.rtve.es/alacarta/videos/los-desayunos-de-tve/cataluna-dara-tarjetas-sanitarias-inmigrantes-sinpapeles-censados-region/1702863/.

* Sílvia Navarro Casado. Licenciada en Derecho, Universidad Autónoma de Barcelona. Máster Oficial en Integración Europea, Universidad Autónoma de Barcelona. silvianavarroc@ub.edu
} 


\section{Resumen}

En el presente artículo se hace una diferenciación entre dos figuras jurídicas: la objeción de conciencia y la desobediencia civil, ambas aplicadas al ámbito sanitario, analizándose asimismo el comportamiento de los profesionales a propósito del Real Decreto 16/2012 de 20 de abril de 2012.

Palabras clave: objeción de conciencia, desobediencia civil, Real Decreto 16/2012, prestación sanitaria, inmigrantes.

\section{Abstract}

This article makes a distinction between two legal figures: conscientious objection and civil disobedience, both applied to the health sector, analyzing also the behaviour of professionals with regard to Royal Decree 16/2012, 20th april 2012.Th.

Key words: objection of conscience, civil disobedience, Royal Decree 16/2012, health provision, immigrants. 


\section{Delimitación de los conceptos y conceptos previos de la objeción de conciencia}

La objeción de conciencia es una conquista moral, reconocida por el Derecho, propia de una sociedad democrática que vive pacíficamente y que respeta a las minorías. Esta figura ético-jurídica no está regulada de manera específica. Se fundamenta en la protección genérica de la libertad ideológica, incluida en la Constitución Española² y para su ejercicio no es necesaria una regulación propia. Sin embargo, la objeción de conciencia, no se puede considerar un derecho fundamental, no cabe hablar propiamente de un "derecho a objetar". En primer lugar, porque no hay un derecho a la objeción de conciencia, propiamente hablando, sino que ésta es una posibilidad que se deriva del derecho fundamental de libertad de conciencia; $y$, en segundo lugar, porque todo el mundo debe cumplir las obligaciones constitucionales y legales. No obstante, puede ocurrir que se admita la objeción de conciencia excepcionalmente, respecto de un deber concreto 3 .

El ordenamiento jurídico, en un sistema democrático, es el encargado de prescribir normas válidas para todos, independientemente de las opiniones morales de cada ciudadano. Sin embargo, en una sociedad plural surge con facilidad el conflicto entre el deber moral y jurídico, siendo éste mismo el núcleo de la objeción de conciencia. La decisión de no obedecer la obligación, impuesta por la norma legal, por razones de desacuerdo moral es una opción que pertenece al ámbito de la ética individual y no del derecho ${ }^{4}$. Esto es así, porque la objeción de conciencia representa un conflicto de valores. En relación a este conflicto, el profesional solicita que se le exima de realizar un deber, puesto que realizarlo supondría lesionar los valores ideológicos, morales o religiosos que él mismo manifiesta.

La objeción de conciencia en el ámbito sanitario puede ser de dos tipos: la propia del profesional (abarca, de manera especial, el aborto, anticoncepción, esterilización, reproducción asistida, eutanasia y suicidio médicamente asistido) y la impropia (atención a los Testigos de Jehová en el sentido de confrontación de conciencias. Por ejemplo, realizar una cirugía mayor ambulatoria sin sangre cuando hay alta probabilidad de que se necesite en la intervención). Ambas resultan cubiertas por el precepto legal, siempre que correspondan a escrúpulos morales y no involucren únicamente conflictos éticos propios de la profesión, como ejemplo, la limitación del esfuerzo terapéutico llegado a un punto de no retorno en la evolución del paciente, donde la continuación del tratamiento seria fútil.

Por otra parte, se debe distinguir la objeción de conciencia legalmente establecida de la reticencia profesional o personal del personal sanitario a actuar en un caso concreto, como suelen ser

\footnotetext{
2 En rigor, la objeción de conciencia es un aspecto del derecho a la "libertad ideológica" establecido por el artículo 16.1 CE

${ }^{3}$ La doctrina del Tribunal Constitucional considera a ésta como la característica principal de la objeción, puesto que su originalidad subyace de la posibilidad de eximir un deber bajo circunstancias concretas y como excepción a la política de actuación general.

4 Para entender esta idea, es muy útil la lectura del Preámbulo en CASADO,M. y CORCOY,M. (coords) Documento sobre objeción de conciencia en sanidad, Barcelona, 2007.
} 
los trasplantes, la investigación, la limitación de recursos para tratar con un nuevo medicamento..., ya que las discrepancias de tratamiento del experto han de ser motivo de deliberación en una sesión clínica o en el Comité de Ética Asistencial (CEA) del centro.

Podríamos afirmar que la obligación moral se ha de atender antes que la jurídica, pero con ciertos matices, ya que existe un límite infranqueable: afecta al ejercicio de la libertad de un tercero y su derecho a un trato igualitario. Puesto que el derecho del paciente prevalece en caso de conflicto con otros derechos. Se ha de garantizar la prestación sanitaria establecida y la objeción del profesional se admitirá siempre que el servicio se pueda cumplir con normalidad. Además, se debe puntualizar que la objeción en el ámbito sanitario es siempre individual, ejercida por los profesionales sanitarios directamente implicados. Esto da lugar a afirmar que a nivel de las instituciones la objeción de conciencia no existe.

Hay que tener muy en cuenta que la objeción es una figura que aflora, de modo especial, en los centros públicos, ya que en los centros de salud privados, y en los concertados, seguramente no se pactarán carteras de servicios "no deseadas" conforme a su ideario. Por tanto, una vez contratado el personal trabajador, éste se adecuará a las necesidades de la cartera de servicios del centro por lo que no tendría sentido alegar una objeción a nivel individual en un servicio del que el centro no dispone. De igual modo, debe tenerse en cuenta que, aunque en los centros concertados no se prohíbe la adhesión de su personal a la objeción de conciencia, este no debe olvidar que ha sido contratado para atender a una prestación pública y que, por tanto, el personal de este centro es un agente público de salud, que debe garantizar la adecuada prestación al ciudadano de un Estado.

Un tema distinto es la objeción de conciencia sobrevenida ${ }^{5}$, que se postulará en un momento determinado del ejercicio de la profesión por parte de un profesional concreto. Pese a ello, insisto que no tendría sentido en las instituciones privadas, puesto que son contrarias a las prácticas médicas que se objetan habitualmente (aborto, anticoncepción, esterilización, eutanasia...) y por tanto ya no ofrecen el servicio en su catálogo.

El ejercicio de la objeción de conciencia, es una alternativa reconocida a los profesionales que estén directamente implicados en la acción sanitaria a la que objetan. No se incluirán, por lo tanto, los auxiliares (planta, celadores o secretarias), así como tampoco podrán declararse objetores aquellos profesionales que tienen el deber de actuar antes y/o después de la pericia objetada. ${ }^{6}$

\footnotetext{
${ }_{5}^{5}$ Por objeción de conciencia sobrevenida se entiende aquella que existe a raíz de que el individuo desarrolle razones derivadas del avance tecnológico, de las modificaciones del catálogo de derechos de los usuarios o de la posible evolución ideológica del objetor.

Además, debe admitirse la posibilidad por parte del profesional sanitario a optar por la objeción de conciencia parcial, que es aquella que surge en casos de límite respecto a la legalidad. Supuestos en los que, formalmente, existe el deber jurídico de actuar pero que las circunstancias determinan que sea discutible la concurrencia de ese deber.

6 "Reflexions sobre la pràctica de l'objecció de consciència en la Interrupció Voluntaria del Embaràs" del Comitè de Bioètica de Catalunya. En este texto por primera vez se clarifica quien puede objetar y quien no. Consúltese
} 
Los profesionales de la salud, disponen de dos vías normativas que reconocen la objeción de conciencia: en su Código Deontológico ${ }^{7}$ y en la Ley de Salud Sexual y Reproductiva y la Interrupción Voluntaria del Embarazo8.

Lo que en cualquier caso debe quedar claro es que la objeción no va más allá de la petición de un trato diferente ante un deber legal. Se solicita la exención de un deber, al que el profesional esta obligado, sin que exista manifestación de la voluntad del mismo para que la ley cambie porque el objetor la considere injusta. Asimismo, sólo se niega a aplicar la ley en una situación concreta.

Es cierto que la objeción de conciencia conlleva en sí misma un carácter de desobediencia al Derecho. Está motivado por la ideología, ya que se infringirá un deber jurídico siguiendo un mandato de conciencia. Si la objeción de conciencia no responde ni a la verdad, ni a la justicia, ni a la excelencia, hay que cuestionarse si es una objeción de conciencia o de conveniencia9 ${ }^{9}$

Por sus características se debe diferencias también la objeción de conciencia de la disidencia y la no colaboración, manifestaciones afines pero no características de la objeción.

Recordemos que los objetores no difunden la idea de la injusticia de la ley, pese a que algunos pudieran pensarlo a título personal. $Y$ tampoco solicitan a nivel legislativo ningún cambio. Simplemente piden ser eximidos de actuar conforme al deber de la profesión, exigiendo respeto por su esfera moral privada.

Aquello que solicita un objetor es ser eximido de la pena de desobediencia y, además, que no se le imponga la obligación de la acción a la que objeta. Si, por el contrario, rechaza la norma jurídica por considerarla injusta, buscando su derogación sin pretender eludir el castigo por el incumplimiento legal, estamos ante la desobediencia civil $\mathbf{1 0}$.

http://comitebioetica.cat/wp-content/uploads/2012/05/objeccio consciencia ig.pdf.

7 Por ejemplo, el Codi deontológic del Col/legi Oficial de Metges de Barcelona en su norma 6 no describe propiamente la objeción de conciencia sino que se hace un reconocimiento implícito de la misma.

En el código del Consejo general de Colegios Oficiales de Médicos, se trata la objeción de conciencia desde diferentes perspectivas. La primera, dedicada a la descripción del concepto, explica qué se entiende por objeción (arts. 32 y ss) y, posteriormente, desarrolla una descripción específica de supuestos en los que el profesional puede responder con un conflicto moral dejando de lado su obligación de atender a su deber, alegando objeción de conciencia. Estos supuestos son: la huelga de hambre del paciente (art.12.4), casos de reproducción asistida (art. 55.2) y la incapacidad para actuar de perito en un juicio oral (art.62).

${ }^{8}$ Ley Orgánica $2 / 2010$, de 3 de marzo, de salud sexual y reproductiva y de la interrupción voluntaria del embarazo, art.19.2 " Los profesionales sanitarios directamente implicados en la interrupción voluntaria del embarazo tendrán el derecho de ejercer la objeción de conciencia sin que el acceso y la calidad asistencial de la prestación puedan resultar menoscabadas por el ejercicio de la objeción de conciencia (...)"

9 "Aproximación a la objeción de conciencia", ALARCOS,F.J., Objeción de conciencia y sanidad, Comares, Granada, 2011, pág.31.

10 Es una figura éticamente legítima oponerse a normas injustas, normalmente típica de los Estados no democráticos. Montes, L.; Marín, F.; Pedrós, F.; Soler, F. ¿Qué hacemos para conseguir que la lucha por una vida digna incluya la exigencia de una muerte digna?, Madrid, (2012), págs. 33-34. 
De ahí que objeción de conciencia no sea lo mismo que "desobediencia civil" ni que "insumisión". En las dos figuras anteriores, se objeta a una ley o los tribunales no reafirman la necesidad de que el individuo cumpla la ley en una situación concreta. Si el desobediente persevera en su actitud, se convertirá en insumiso.

\section{España y el Real Decreto 16/2012, de 20 de abril}

A raíz de la entrada en vigor el pasado 20 de abril de 2012 del Real Decreto 16/2012 referente a medidas urgentes para garantizar la sostenibilidad del Sistema Nacional de Salud y mejorar la calidad y seguridad de sus prestaciones, se limita la atención primaria a inmigrantes "sin papeles", aunque se han aceptado algunas excepciones posteriores -en concreto en los casos de enfermedades crónicas y asistencia en urgencias- pero la atención regular en los Centros de Atención Primaria queda prohibida. Algunos profesionales sanitarios han alzado la voz en contra de tales medidas, invocando la objeción de conciencia para que este colectivo reciba la atención sanitaria necesaria, amparándose en que "la salud es un derecho universal". Pese a que esta última afirmación es indudablemente cierta, la figura ética y jurídica a la que se han acogido estos profesionales sanitarios no es la adecuada. El presente artículo pretende poner de manifiesto que lo que en la práctica ha sido presentado como objeción de conciencia es, en realidad, una manifestación de desobediencia civil.

La situación vivida en abril de 2012 ha dado lugar a una confusión de términos. Desde la presentación de estas nuevas "medidas de recorte" por parte del gobierno español, numerosos Colegios profesionales relacionados con las actividades sanitarias han ido manifestando su disconformidad con las medidas expuestas en el mismo.

Haciendo un breve resumen, mediante el citado Real Decreto se priva de asistencia médica a todo aquel que no posea la tarjeta sanitaria y está corresponderá únicamente a los ciudadanos que residan legalmente en España. Asimismo se hace indispensable la tarjeta sanitaria para recetas, atención primaria y consultas externas ${ }^{11}$.

Cabe mencionar que la Sanidad en España, según la Ley General de la Seguridad Social ${ }^{12}$, pretendía ser un derecho universal; no ligado a la cotización ni a la residencia, dando una cobertura de alcance universal y gratuita.

\footnotetext{
${ }^{11}$ Es conveniente analizar el desarrollo del Real Decreto 16/2012 en el sentido de los beneficiarios, usuarios y los requisitos que deben cumplir para recibir atención sanitaria en el sistema de salud público. Incluido en el Real Decreto 1192/2012, de 3 de agosto se modifica la Ley 16/2003, 28 de mayo. En concreto, consúltense los artículos: art. 3 (para qué sirve la tarjeta sanitaria); 3 bis. 2 (quien es titular de la tarjeta sanitaria) y disposición final 7 a (tarjeta indispensable para dispensar recetas).

12 LGSS en su artículo 1 describe el derecho de los españoles a la Seguridad Social, remitiendo al artículo 41 de la Constitución Española; " Los poderes públicos mantendrán un régimen público de Seguridad Social para
} 
La Carta de Derechos Fundamentales de la Unión Europea incluye el derecho de asistencia sanitaria dentro del precepto "Solidaridad" calificando este listado de derechos, como valores indivisibles y universales. Son derechos que se atribuyen a las personas por el mero hecho de serlo, sin necesidad de ostentar nacionalidad o pertenecer a un colectivo concreto ${ }^{13}$.

Y precisamente estas características son las que el Real Decreto quebranta. Se priva de asistencia primaria a los residentes ilegales así como a las personas no portadoras de la tarjeta de la seguridad social, haciendo de este modo imposible su acceso a la sanidad pública. Aunque posteriormente se ha introducido la matización de que no se privará a estas personas del acceso a urgencias y visitas sucesivas en el caso de enfermedades crónicas ${ }^{14}$.

Trabajadores del sector sanitario, de forma no coordinada, empezaron a emitir comunicados utilizando la objeción de conciencia de manera indiscriminada y haciendo un uso no aceptable del término. En estos comunicados los profesionales de la salud entienden el "derecho a curar" como la plasmación de la voluntad del colectivo de la profesión sanitaria del que debería el derecho a "no actuar" conforme a la política legal establecida, llegando a publicitar la campaña por canales de difusión externos a la profesión y visibles en los medios.

Sin embargo, olvidaron que el término objeción se refiere al acto concreto que interpela la moral personal y en este caso, el objetivo era no cumplir con las pautas que bajo el título normativo se obligaba (no asistencia sanitaria al inmigrante indocumentado en sentido sanitario) atendiendo, en primer lugar, al beneficio del paciente y, además, instaurando esta actitud como una conducta colectiva $^{15}$.

todos los ciudadanos, que garantice la asistencia y prestaciones sociales suficientes ante situaciones de necesidad, especialmente en caso de desempleo. La asistencia y prestaciones complementarias serán libres."

13 En el art.34 CDFUE se recoge "seguridad social y ayuda social" y en el art.35 CDFUE "la protección de la salud". En ellos se refleja que el derecho a asistencia sanitaria no es un derecho fundamental; sin embargo, si lo es el derecho a la protección de la salud que está considerado derecho fundamental. Ello significa que la salud, es un derecho establecido como universal y protegido al más alto nivel.

14 Verdaderamente han sido cruzadas paralelas, ya que la aceptación de la atención a los inmigrantes con enfermedades crónicas se produjo días después de la anunciación del Real Decreto 1192/2012.

Caben destacar entre las particularidades de la atención al inmigrante irregular (tanto de tipo urgente como de visita sucesiva, es decir, urgencias y/o consultas de seguimiento por enfermedad crónica) se deberá financiar por al país de origen siempre que exista convenio de colaboración bilateral, y siempre que el médico considere que se trata de una urgencia.

Según el director de Servicios del Sistema Nacional de Salud y Farmacia, el Dr. Agustín Moreno, lo que prima es el riesgo vital para su salud y ante éste la persona será atendida en cualquier caso.

Consúltese, entre otra, la noticia: "Cobrar o no cobrar la sanidad a los inmigrantes, así actúa cada CCAA" EL MUNDO, de 14 de septiembre de 2012. En ella además de desarrollarse esta medida, explicita como se actuará en cada Comunidad Autónoma al respecto.

15 Hasta el punto de firmar un manifiesto colectivo, al cual se adhirieron 1.744 profesionales, en su mayoría médicos, aunque también enfermeras. El texto es el siguiente:

"Per la present manifesto la meva voluntat de voler exercir l'objecció de consciència davant la norma 
Visto lo anterior, podemos afirmar que estos profesionales se manifestaban no sólo negándose a cumplir la obligación legal por ser contraria a su conciencia, pretendiendo con ello ser eximidos de la obligación y de la pena de desobediencia, sino que, además, cuestionan la legitimidad de la norma. Por tanto, definitivamente estamos ante una actitud de desobediencia civil para con las obligaciones que el citado Real Decreto les impone.

Tras acumular numerosos titulares de prensa en diferentes partes de España ${ }^{16}$ surgen las primeras declaraciones que ponen en entredicho la teoría de la objeción de conciencia respaldada hasta la fecha por los expertos. El presidente del Consejo General de Colegios Oficiales de Diplomados en Enfermería de España realiza una declaración pública aclarando que "atender a los inmigrantes ilegales sin tarjeta sanitaria comportaría un delito de desobediencia civil, no una objeción de conciencia", clarificando con estas palabras que la técnica utilizada por sus compañeros de profesión no es la adecuada ${ }^{17}$. Se está desobedeciendo una norma de rango estatal, no se actúa bajo la influencia de convicciones y creencias ideológicas y sí bajo la prudencia profesional.

A esta interpretación, sin temor a reconocer que la práctica llevada a cabo no era propiamente una objeción, se sumaron otros colectivos del ámbito sanitario, admitiendo que aquello que solicitan es el cambio de la disposición, asumiendo las posibles represalias y aceptando la inviabilidad de la objeción de conciencia en estos casos ${ }^{18}$.

promulgada pel Govern espanyol en el RD 16/2012 que deixa sense prestació sanitària a persones que fins ara havíem atès a les nostres consultes. La meva lleialtat amb els pacients fa que no sigui possible faltar al meu deure ètic professional i incórrer en l'abandó (...) És la meva voluntat poder seguir atenent a les persones que són els meus pacients i que no tenen permís de residència".

Texto facilitado por la campaña " Derecho a curar" respaldada por Médicos del Mundo (una organización de profesionales sanitarios sin ánimo de lucro).

16 Desde determinados Colegios de profesiones sanitarias concretas, así como centros de salud e incluso profesionales de la medicina a título propio.

Véanse como ejemplos; el comunicado de las enfermeras de Murcia en el que declaran su voluntad a unirse a la objeción de conciencia, www.enfermeriademurcia.org/noticias/noticia.asp?ent=594; el comunicado de la Sociedad Española de Medicina Familiar y Comunitaria (SEMFyC) en el que se manifiestan en contra del Real Decreto, a favor de la objeción de conciencia y se potencia la creación de un registro de objetores exclusivamente para esta causa, véase el mismo en, http://semfyc.es/es/noticias/destacadas/\%20listado/ Atendemos personas noasegurados Comunicado RD Regsitro objeci\%F3n/.

E incluso recientemente, la "Red de objetores" ha sido galardonada como una de las mejores ideas en sanidad este 2012. Consúltese la noticia de 21 de noviembre de 2012 en el siguiente enlace; http://semfyc.es/es/noticias/destacadas/listado/PremioMejoresIdeas 2012/.

17 Entrevista concedida a la Cadena Ser en fecha 9 de agosto de 2012 por el Dr. Máximo González Jurado, presidente del Consejo General de Colegios Oficiales de Diplomados de Enfermería. Para conocer la interlocución véase la nota de prensa en, http://www.cadenaser.com/sociedad/articulo/atender-inmigrantestarjeta-sanitaria-puede-considerarse-objecion-conciencia/csrcsrpor/20120809csrcsrsoc 11/Tes.

18 Así se pronunciaron en un comunicado de la Organización Colegial de Enfermería de España, a fecha 9 de agosto de 2012, Madrid, véase el mismo en el siguiente enlace http://www.enfermeriacanaria.com/wptfe/wpcontent/uploads/12-08-09-NP-Matizacion-Consejo-Enfermeria-RD-casos-no-beneficiarios-SNS.pdf. 


\section{Conclusiones}

En este artículo se parte de la premisa de que no toda actuación "en conciencia" debe ser considerada objeción de conciencia. Para serlo, la moral, en este caso del profesional sanitario que participa activamente y al que se le exige llevar a cabo el deber, ha de anteponerse a la obligación.

La objeción de conciencia es una excepción siempre sujeta a la interpretación de los tribunales y las leyes. Ha de ser coherente, individual y responsable. Se ha de garantizar su ejercicio, y en caso de conflicto, éste se debe resolver en los propios centros o incluso recurrir a los Comités de Ética Asistencial para solucionarlo.

Por este motivo, utilizar el concepto de objeción de conciencia cuando en realidad aquello que se pretende es incumplir deliberadamente, de forma no violenta, ciertas leyes que se consideran injustas por parte del colectivo sanitario, como medio para presionar políticamente y promover su cambio, yendo más allá de la abstención a una determinada práctica sanitaria. Con harta frecuencia, se hace un uso indiscriminado, frívolo y banalizador del concepto de objeción de conciencia, amparándose en una corriente de objeción generalizada, puesto que generalmente en casos extremadamente sensibles, como es la atención a un colectivo social discriminado, el profesional muestra empatía con el mismo y objeta con mayor facilidad sin tener en cuenta que su conducta no se corresponde con la voluntad de realizar un comportamiento que difiere de lo instado por el mandato.

En el presente caso, no sólo se analiza el Real Decreto 16/2012, de 20 de abril, por el que se regula la condición de asegurado y de beneficiario a efectos de la asistencia sanitaria en España, con cargo a fondos públicos a través del Sistema Nacional de Salud, es injusto, sino que, además, se decide atender al colectivo inmigrante aunque no posea tarjeta sanitaria; además de exponer reiteradamente la voluntad de que la legislación cambie.

Dentro de lo que muchos expertos consideran justo, la atención al paciente "sin distinción", se incluye que la objeción de estos profesionales sea efectiva siempre que se atienda fuera del horario laboral e incluso fuera de las consultas que el centro médico público o concertado ofrece para garantizar las prestaciones sanitarias públicas, puesto que estas instalaciones están habilitadas y destinadas por precepto legal, a la atención sanitaria de unos determinados pacientes, portadores de la tarjeta sanitaria.

Atender a los inmigrantes, o personas que no posean la tarjeta sanitaria en vigor, dentro del horario laboral y en las infraestructuras y con los medios de las cuales el profesional sanitario no es titular único, significa desobedecer la ley ${ }^{19}$. Y el precio a pagar por una desobediencia es muy distinto al de ser objetor. La objeción de conciencia y la desobediencia no se tratan como vías incompatibles,

\footnotetext{
${ }_{19}$ Cabe destacar que la conducta "atender, en horario laborable, en un centro de salud público, a personas que carecen de tarjeta sanitaria" no está reflejada en los arts. 95 y 96 referentes al personal estatutario del RD como conductas que suponen "faltas" previstas como propias del colectivo.
} 
sino que lo normal es que el desobediente justifique su conducta en la base al principio moral; ello puede interpretarse como que la desobediencia, en este caso la atención a los ciudadanos españoles al margen de ser beneficiarios de tarjeta sanitaria e incumpliendo el Real Decreto, justifican su conducta en el principio moral (para la protección de la salud debe atenderse de forma universal). Ello puede interpretarse como que la desobediencia necesita los fundamentos ético-morales que respalden la decisión y voluntad de cambio. ${ }^{20}$

Lo sorprendente de este RD es que no se prevé un apartado para las sanciones jurídicoadministrativas en el caso de incumplimiento o comisión de conductas que vayan en contra de lo que en él mismo se establece, y ello supone, una imposibilidad de sanción sobre aquello que no está previsto por ley.

Aunque no haya un tipo que corresponda a sanción por esta conducta, sí que existen sanciones disciplinarias que la Administración puede ejercer para sancionar al personal estatutario que no cumple con el RD; divididas como faltas leves, graves o muy graves y ello dará lugar a una serie de sanciones, tales como la separación del servicio, el traslado a distinto centro incluso de Comunidad Autónoma, suspensión de funciones, apercibimiento....(arts. 72 y 73 Estatuto del Personal Estatutario ${ }^{21}$ )

En estos casos la imposición de la sanción no podrá ser automática, iniciándose un procedimiento (art.74.2 Estatuto del Personal Estatutario). Aunque en los procesos en los que se aleguen faltas graves o muy graves, se puede solicitar en régimen de medidas cautelares la suspensión provisional de funciones del interesado (art.74.1. del Estatuto del Personal Estatutario).

El experto, agente público está requiriendo, con su actitud y su afiliación a la campaña de médicos del mundo.org, el sentido de la justicia de la comunidad invocando en su favor valores éticos y disconformidad con la obligatoriedad en la atención del Real Decreto. Esta actitud desobediente plantea problemas agudos y muestra fisuras con la ley establecida.

A priori, sólo por tener intención de incumplir el Real Decreto sin muestra efectiva de situaciones concretas y comentarios críticos al Real Decreto no puede haber sanción ni discriminación hacia el profesional o centro que promuevan dicha actitud.

Es necesario reconocer que la campaña de Médicos del Mundo.org ha logrado despertar un ánimo colectivo de colaboración entre los profesionales sanitarios ante la injusta medida legal que impide que el derecho a la salud sea ejercido en el Estado Español por todos sus habitantes de forma equitativa. Aun así, debe observarse que la equidad no es aquello que preserva el Real Decreto, una norma legal aquello que defiende es la igualdad o en detenimiento el trato más igual posible. En este

20 GASCÓN,M., Obediencia al derecho y objeción de conciencia, Centro de estudios constitucionales, Madrid, 1990, págs.. 203 a 206.

${ }^{21}$ Estatuto del Personal Estatutario está recogido en la Ley 55/2003, de 16 de diciembre, del Estatuto marco del personal estatutario en servicios de la salud. Por esta ley, entre otros preceptos, se disponen las sanciones disciplinarias en los servicios de salud. 
caso es una premisa indiscutible del éxito de la campaña frente al frívolo Real Decreto es el papel del colectivo marginal y sensible, que los afectados juegan. Pese a todo, la campaña tiene una mala base y desde el punto de vista jurídico tan sólo será sostenible si se aclaran los conceptos y no se utiliza a los afectados como único argumento.

Ante este Real Decreto, lo que procede es la reivindicación por parte de los trabajadores del ámbito sanitario; respetar e igualar los derechos de todos los pacientes de forma adecuada, llamando al movimiento en el que se involucran por su nombre, siendo conscientes que se desobedece el Real Decreto y aceptando las posibles consecuencias de tal práctica, las cuales aunque no tipificadas como sanción jurídico-administrativa, existen como sanciones disciplinarias y pueden suponer "graves" consecuencias para el profesional de la salud.

Fecha de recepción: 1 de diciembre de 2012

Fecha de aceptación: 24 de enero de 2013 